\title{
LUT
}

University

\section{Exploring the Pitfalls of Systemic Innovations for Sustainability}

\author{
Tura Nina, Mortimer Genevieve, Kutvonen Antero
}

This is a Author's accepted manuscript (AAM) version of a publication

published by Palgrave Macmillan, Cham

in Innovation for Sustainability. Palgrave Studies in Sustainable Business In Association with Future Earth.

DOI: 10.1007/978-3-319-97385-2_9

Copyright of the original publication: (c) The Author(s) 2019

Please cite the publication as follows:

Tura N., Mortimer G., Kutvonen A. (2019) Exploring the Pitfalls of Systemic Innovations for Sustainability. In: Bocken N., Ritala P., Albareda L., Verburg R. (eds) Innovation for

Sustainability. Palgrave Studies in Sustainable Business In Association with Future Earth.

Palgrave Macmillan, Cham

This is a parallel published version of an original publication.

This version can differ from the original published article. 


\title{
EXPLORING THE PITFALLS OF SYSTEMIC INNOVATIONS FOR SUSTAINABILITY
}

\author{
Nina Tura \\ Postdoctoral researcher \\ LUT University, Finland \\ Email: nina.tura@lut.fi
}

\section{Genevieve Mortimer}

Project manager

Climate-KIC Australia

Email: genevieve.mortimer@googlemail.com

\author{
Antero Kutvonen \\ Postdoctoral researcher \\ LUT University, Finland \\ Email: Antero.kutvonen@lut.fi
}

\begin{abstract}
Systemic innovation can deliver influential sustainability solutions, but it occurs rarely. Increasing sustainability challenges firms to improve the system as a whole through broadening their engagement by game-changing innovations. This empirical case study explores the challenges faced by Finnish business leaders that hold back attempts at systemic innovation for sustainability. The challenges were identified to be caused by structural impediments, uncertainty avoidance and conflicting aims within and between firms. These in turn manifest as cumulative problems in managing opportunity costs, outcome uncertainties and communication problems along the entire innovation process. The study highlights the need for firms to acquire capabilities for sustainability by focusing on building capabilities in open innovation, evaluating and seizing radical opportunities, and reconfiguring the organisation for systemic innovations for sustainability.
\end{abstract}

\section{Introduction}

Innovation plays an important role in the sustainability journey (Lin and Tseng, 2016; Silvestre, 2015). Recent management literature (e.g. Boons et al., 2013) advocates for firms to shift from a focus on a linear supply chain towards systems building and engaging with external stakeholders (Adams et al. 
2016; Inigo and Albareda, 2016; Medeiros et al., 2014) to improve the entire system through accelerated and transformative change (e.g. Nidumolu et al., 2009; Quist and Tukker, 2013). Taking the lead in shaping the market/industry transformation may grant major strategic advantages enabled by radical innovations aiming at systems changes (Boons et al., 2013; Hansen et al., 2009; Seebode et al., 2012).

While the ambition beyond incremental change exists, the evidence suggests that firms fail largely in delivering game-changing innovations for sustainability (Accenture, 2015), and produce instead only incremental innovations inadequate for solving the sustainability challenges (Van den Bosch et al., 2015). There is a fundamental gap in moving from ambition to execution. In this study, we heed the recent call from Xavier et al. (2017) to explore the implementation of innovation for sustainability by asking: What are the main challenges in delivering systemic innovations for sustainability?

We have built a literature-based framework and added an empirical perspective to the debate about inaction by exploring the perceptions of business leaders in a multi-industry sample of globally operating Finnish companies. The data comprised 27 interviews in 13 companies. We found the respondents to converge on common challenges, regardless of the industry or the specific context, which could be explained by current dynamic capabilities not being able to address the idiosyncratic demands of developing systemic innovations for sustainability.

Our empirical results support the existing literature about the challenges of systemic innovations for sustainability (Boström et al., 2015; Mignon and Bergek, 2016; Roscoe et al., 2016; Silvestre, 2015), and according to the results, firms face three categories of inter-connected challenges: structural impediments, uncertainty avoidance and conflicting aims within and between firms. Each challenge is connected to lacking capabilities in open innovation, evaluating and seizing radical opportunities, and reconfiguring the organisation for systemic innovations for sustainability.

\section{Systemic innovations for sustainability}

Sustainability is a journey towards engaging environmental, social and economic goals to deliver societal benefits from business activity (Elkington, 1997). Sustainability represents the balancing of internal goals with external dynamics (Lozano, 2015) to optimise collective value in the long term. Firms are driven to broadening their engagement and acting to improve the system as a whole (Gaziulusoy and Brezet, 2015; Adams, 2016). However, this approach has not been realized yet (Accenture, 2015).

Innovation could fill this gap through delivering new technologies, tools and processes, and ultimately a new mind-set (Adams et al., 2016; Medeiros et al., 2014). Innovations for sustainability are understood as commercialised inventions (e.g. products, technologies, services, processes, and business models) that aim at creating economic, environmental and social value (e.g. Seebode et al., 2012; 
Schiederig et al., 2012; Schaltegger and Wagner, 2011). Taking them to the systemic level, i.e. systemic innovations for sustainability, can also include wider society-level changes, e.g. market and user practices, policies, regulations, culture, technologies, or firm management practices (Gaziulusoy and Brezet, 2015).

Such innovations consider the impacts across the entire supply chain and can tackle sustainabilityrelated challenges (Boons et al., 2013; Lin and Tseng, 2016), create sustainable business value (Bocken et al., 2014), and deliver an overall positive impact on the system (Hansen et al., 2009). Innovating on the systemic level provides improved options for game-changing or 'radical' innovation (Quist and Tukker, 2013) that may reposition firms to lead the market/industry transformation and impose change on the competition (Schaltegger and Wagner, 2011). Systemic innovations for sustainability introduce complex or even paradoxical system effects that go beyond simple cause-and-effect management towards systems building (Adams et al., 2016) and require specific capabilities to deliver them.

Systemic innovation increases a firm's interdependence with its stakeholders and environment (Eccles, 2014). By managing their dependence on complex external systems and supply chains, firms may create networks that provide resilience. However, this requires the building of collaborative (open innovation) skills with greater network management capabilities (Van den Bosh et al., 2015). This collaboration shapes the evolution of supply chains (Silvestre, 2015) and provides seeds for sustainable transitions (Markad et al., 2012). Hence, systemic innovation requires adopting a new set of skills, capabilities and approaches (Medeiros et al., 2014; Seebode et al., 2012) geared towards collaboration and supply network management (Roscoe et al., 2016).

Adaptation to changing business environments is accomplished through the application of dynamic capabilities (Teece et al., 1997). They allow reconfiguration of the firm's resources and knowledge capacities to achieve higher technical and/or evolutionary fitness in their business environment (Teece, 2007; Helfat et al., 2007) and facilitate business model experimentation (Teece, 2017). Dynamic capabilities are context-dependent (Eisenhardt \& Martin, 2000), which means that what enables success in one environment may obstruct performance in another.

Success built on high technical and evolutionary fitness, i.e. strong economic innovation performance and fit with the core market, can hold back transitioning to systemic innovation. Systemic innovations change the boundaries of the firm, eroding thus evolutionary fitness and reducing the effectiveness of existing dynamic capabilities. Knowledge and capability path dependencies introduce inertia to change processes (Eisenhardt and Martin, 2000), which increases the financial and performance costs associated with capability reconfiguration. To maximise long-term sustainable value, non-efficiency perspectives need to accompany decision-making with e.g. alliance, innovation or stakeholder engagement issues. 
Similar challenges have been identified in transitioning to open innovation (Lichtenthaler and Lichtenthaler, 2009), where sustainable systemic innovation introduces further challenges of deeper stakeholder dependence and coordination. Additionally, systemic innovations call for acquiring and exploiting synergies between open and radical innovation capabilities (Slater et al., 2013). To accomplish this, the dynamic capabilities need to be updated to accommodate a broader range of stakeholders, to allow effective use of 'distant' and external knowledge, and to address the requirements of open innovation (Behnam et al., 2018; Teece, 2007; Lichtenthaler and Lichtenthaler, 2009).

Acquiring, strengthening and exploiting capabilities successfully in the pursuit of systemic sustainable innovation is a multi-level management challenge (Lichtenthaler, 2011). Interdependent changes need to be introduced on the levels of organisational structure, culture, leadership, and strategy, as well as individual skills and project-level decision-making. Dynamic capabilities are often built from benchmarking relevant practices and routines in the familiar market environment and the competition (Teece et al., 1997; Teece, 2007) through experimentation and experience. However, as the systemic transition is only at its beginning, organisations have few best practices to draw from, while complexity prevents relying exclusively on 'ad-hoc problem solving' (Winter, 2003).

\section{Methods and research design}

Our research is a qualitative, explorative multiple case study in a multi-industry context in Finland. An inductive case study approach was selected due to its suitability for examining a topic with scarce empirical research (Eisenhardt and Graebner, 2007; Yin, 2014). We have applied theoretical sampling (Eisenhardt and Graebner, 2007) to identify cases of firms with serious commitment to sustainability. The data comprises 27 in-depth, recorded and transcribed semi-structured interviews of 40 informants from 13 established, internationally operating companies from Finland. The participants were experienced senior managers working at environmental, innovation and business management, with titles ranging from CEOs to environmental and $\mathrm{R} \& \mathrm{D}$ managers. The companies included three large companies from both energy and wood industries, two large companies from process industry, one large company from steel, waste-management and digital business industries. In addition, the data was gathered from one large and one medium-sized consulting organizations focusing on regional business development.

Sustainable development has a mature role in Finnish companies, authorities, consumers, and the society. The interviewed firms had a long history of sustainability reporting, and had introduced sustainability-related products, such as bio-oil and materials to replace plastic packaging of food. While systemic innovations require collaboration between science, government, industry and civil society, the study focuses on exploring the perceptions of firms to create deeper understanding of their perspectives. 
Through open-ended interview questions, the participants were asked to express their feelings on how sustainability was concerned in their business development and innovation activities. More specific questions were asked to identify the challenges, problems, tensions, and uncertainties of executing sustainability innovations. In addition, the interviews concerned the future needs and challenges to execute more innovations for sustainability.

The data analysis followed content analysis methods with open coding to understand the managerial challenges in making sustainability-related decisions. During the coding, we noticed recurring themes including 1) external factors (i.e. structural impediments), 2) internal decision-making factors (leading to uncertainty avoidance), and 3) increased complexity (due to conflicting aims). The data analysis was continued by employing cross-case analysis and axial coding (Corbin and Strauss, 2015) to focus on specific sustainability innovation -related tensions and uncertainties. The analysis was founded on themes identified in the literature (see table 1). The emerging results were presented to managerial and academic audiences (Yin, 2014), after which we made minor iterations and clarified the identified groups of challenges.

\section{Results - synthesis of the perceived key challenges}

We found that the challenges identified by scholars could be positioned into three categories: 1) structural impediments, 2) uncertainty avoidance, and 3) conflicting aims within and between firms. Some challenges were interlinked and overlapped between categories. The challenges identified in the literature are synthesized in table 1. This table is complemented with empirical insights from our data with the focus on related effects on innovation management. The literature led our empirical research to understand where capabilities fall short in managing systemic innovation for sustainability.

Table 1. Overview of the challenges of delivering systemic innovations for sustainability

\begin{tabular}{|c|c|c|}
\hline $\begin{array}{c}\text { Challenge categories: } \\
\text { theoretical insights }\end{array}$ & $\begin{array}{l}\text { The effects on innovation } \\
\text { management: empirical insights }\end{array}$ & Empirical insights \\
\hline \multicolumn{3}{|c|}{ Structural impediments } \\
\hline $\begin{array}{l}\text { Market structure } \\
\text { Infrastructure challenges } \\
\text { Institutional and } \\
\text { regulatory challenges } \\
\text { Financial capital } \\
\text { availability challenges }\end{array}$ & $\begin{array}{l}\text { Dominating incumbents focus on } \\
\text { incremental market innovations that } \\
\text { fit existing structures. } \\
\text { Institutional misalignment between } \\
\text { different government levels or } \\
\text { sectors cause adoption challenges } \\
\text { for innovation. }\end{array}$ & $\begin{array}{l}\text { There is much debate between different } \\
\text { actors inside industries about the } \\
\text { sustainability of different choices (e.g. } \\
\text { related to wood as constuction } \\
\text { material). This debate has not always } \\
\text { stayed on facts as companies defend } \\
\text { their own business perspectives instead } \\
\text { of seeing the overall sustainability } \\
\text { benefits. } \\
\text { When viewed on a European level, } \\
\text { regulatory environments can be } \\
\text { misaligned and confusing, such as with }\end{array}$ \\
\hline
\end{tabular}


Mignon and Bergek, 2016;

Mylan et al., 2015 of the classifications of renewable materials that vary between countries (for example peat is classified in Sweden as a renewable material and in Finland it is not).

\section{Uncertainty avoidance}

High investment costs Innovations for sustainability are

Technological and commercial uncertainty

Regulatory uncertainty

Organisational uncertainty

Social uncertainty

Key literature sources: Ambec and Lanoie, 2008; Anttonen et al., 2013; Hall et al., 2011; Mignon and Bergek, 2016; Noppers et al., 2015; Lopez et al., 2017; Silvestre, 2015; Vezzoli et al., 2015 expensive by traditional measures, leading to high opportunity costs. Regulatory uncertainty prevents investment decisions.

Discontinuity of political decisions, and changing policies create outcome uncertainties.

New technologies involve risks (economic, social, environmental) and high uncertainty, as they lack references.

Sustainability demands and innovation actions create costs, but benefits are hard to valuate financially, making project-level profitability comparisons difficult.
Respondents see high political risks as politics and regulations related to sustainability may change (fast). Political changes may lead to a loss of operation conditions.

There exists a technological dilemma as old technologies are not sustainable enough. However, new technologies lack of references, which is why companies are not permitted to put new technologies into action.

The society needs sustained profitable economic activity to function, but companies (and societal actors) find it hard to estimate the economic sustainability of the sustainability investments.

\section{Conflicting aims within and between firms}

Conflicts for business timeframes

Conflicts between actors' perceptions Increased complexity of networks

Interaction and communication challenges Information and knowledge gap challenges

\section{Key literature sources:}

Boström et al., 2015; Eccles, 2014; Gaziulusoy and Brezet, 2015; Hahn et al., 2010; Lockett et al., 2011; Mignon and Bergek, 2016; Mylan et al. ,2015; Roscoe et al., 2016; Quist and Tukker, 2013

\section{Existing performance measures,} decision structures and practices are geared for a shorter business timeframe.

Deciding between contradictory sustainability goals and opportunity costs hinder innovation actions.

Increased dependency on suppliers and networks requires identification and management of partners' capabilities and involvement. In global networks, geographical and cultural gaps complicate matters further.

Focusing on internal business goals obstructs collaborative innovation.

Communication challenges lead to commercial uncertainties and an inability to leverage sustainability innovations.
Companies are impatient with waiting for results of sustainable development initiatives (e.g. monetary benefits) that are not visible in the short-term.

Social and economic sustainability goals can be contradictory and the interpretation of responsibility may vary between actors (e.g. societal actor and company representative).

Companies and organizations need active and knowledgeable partners to sustainability initiatives, but higher level sustainability goals are weakly implemented in many companies.

There is a need to increase information about possibilities for collaboration and innovation in terms of sustainability. Especially SMEs lack of knowledge of what is being done in other companies and universities. 
Information and knowledge gaps

hinder interorganizational learning

and innovative collaboration.

Structural impediments include challenges related to market structures and infrastructure. The incumbent actors' dominance on markets, together with the increased supply network coordination promote the stability of existing businesses, setting focus on incremental development (Mylan et al,. 2015). Lack of knowledge, physical infrastructures and financial capital hold back innovations as well (Mignon and Bergek 2016). Institutional misalignment, varying standards and informal institutional challenges may impede innovation further (Mignon and Bergek, 2016, Boström et al., 2015). Structural impediments were largely seen by the interviewees to be beyond the direct influence of firms. Still, the firms were aware of the institutional environment and adapted their activities accordingly.

Innovation for sustainability often involves high technological and commercial uncertainty related to a lack of available knowledge, resources, competences and capabilities (Vezzoli et al., 2015). For instance, companies' or supply chains' lacking resources create challenges in technological feasibility (Hall et al., 2011), while individual adopters' resources and behaviour influence their willingness to pay for innovation (Noppers et al., 2015; Anttonen et al., 2013).

Uncertainty avoidance is linked to high investment costs (Ambec and Lanoie, 2008) and unpredictable regulatory environments (Lopez et al., 2017). Organisational uncertainty comes also from matching sustainability with other strategic goals, and from challenges in seeing the societal side-effects (Hall et al., 2011; Silvestre, 2015).

Our empirical results showed that uncertainty avoidance was strong in holding back investments in systematic innovation for sustainability. As informants explained, the ideas exist but the willingness to take the business risks is missing. Firms favour more traditional projects where returns are perceived to be more reliable. As an example of this risk aversion, one informant had discontinued piloting a new bio-heating plant because they wanted to be certain that their solutions work perfectly from technical and commercial perspectives without needing to invest in testing and development. Political uncertainty at European, national and regional levels complicate sustainability investments and the implementation of sustainable innovations. The informants noted especially that compliance to the external demands (regulations) might simply be too expensive or demanding to execute. To anticipate ever-tightening regulations, some firms have their suppliers follow more stringent environmental standards than the authorities do. Still, most firms simply avoid unclear regulatory environments and refrain from nonmandatory sustainability investments. The uncertain but strong political influence polarises sustainability investments to patterns of over- and underinvestment. 
Conflicting aims within and between firms are linked to conflicts between the actors' perceptions (Hahn et al., 2010) and increased dependency on networks with a variety of actors, relationships, and different incentives and objectives (Lockett et al., 2011; Eccles, 2014). These are closely connected to challenges in interaction and communication (Mignon and Bergek, 2016; Roscoe et al., 2016; Quist and Tukker, 2013), information asymmetry and lack of transparency between actors, which may lead to suboptimal coordination and learning (Boström et al., 2015). Furthermore, sustainability innovations are characterised by challenges in coping with short-term business goals and long-term objectives (Gaziulusoy and Brezet, 2015).

All the companies in our study acknowledged that some sustainability efforts are needed to maintain a "license to operate", and that sustainability has a definite impact on investment priorities. However, this was often seen as sacrificing financial performance to satisfy sustainability goals. Furthermore, the companies saw that systemic effects were neglected also by the authorities as they often forget crosseffects and put efforts especially on activities that are currently present in the media or by political actors. The notions of sustainability may differ greatly among the involved actors and managing divergent stakeholder interests was claimed to be exceedingly challenging in complex networks. Managers acknowledged the importance of interfirm cooperation, but admitted that most sustainability actions were still internal, without a connection to the actions or strategies of their stakeholders. Therefore, cooperative open innovation capabilities were underdeveloped. Communication challenges also hamper firms' abilities to capture value from sustainability projects, and information and knowledge gaps exacerbate many of the problems.

The three categories presented above correspond to a division to external (industry-level) factors, internal factors that complicate decision-making, and relational factors in stakeholder interaction. While firms are experienced in applying dynamic capabilities for internal resource reconfiguration and environmental alignment, the pursuit of systemic innovations challenges the familiar conceptions of firm boundaries. Firms need to cope with extending the breadth and depth of interaction with their business environment, which may be beyond their current capabilities.

The results paint a picture of self-reinforcing conditions of inertia that work against the transformation towards systemic sustainability in innovation practices. The market is structured to favor incremental development and stability over building radical innovation capabilities while interaction and communication challenges complicate concerted efforts and collaborative innovation. With such adverse conditions navigating the transition towards systemic innovations for sustainability requires dedicated strategic action and capability building. 


\section{Organisational roots of inaction}

Our initial content analysis showed how firms were struggling with transforming sustainability from a marginal add-on to a systemic strategy. They saw benefits in systemic sustainability for innovation, but hesitated to invest due to a perceived lack of information and understanding of sustainability interactions, associated costs and outcomes. In other words, we found empirical support for the previously understood challenges with systemic innovation for sustainability.

Sustainability development can be described as a shift in business strategy from a single-bottom line to a triple-bottom line (Elkington, 1997), and now increasingly to the multi-dimensional systems approach (Adams et al., 2016). While the transition to the triple-bottom line already added environmental and community impacts to be considered as business outputs, the systemic view forces firms to strategise and act in new ways. Firms need to be increasingly context-specific and networked, focusing on engaging external stakeholders (e.g. Silvestre, 2015) and improving entire systems (Adams et al., 2016). In the systemic view, sustainability business lies in a complex web of influential actors.

The perceived challenges are amplified in transitioning to a systemic approach, as the idiosyncratic characteristics of systemic innovation for sustainability challenge former capabilities in novel ways. As profitable systemic innovation opportunities are nested in a web of stakeholder interactions and may require radical innovation, sensing and seizing opportunities involves greater uncertainty, collaborative effort and reconfiguration of organisational resources. The influence of undeveloped capabilities manifests as decision-making problems in the outcomes and alternatives of evaluating innovation projects throughout the innovation process, and communicating them to capture the intended value, as illustrated in figure 1.

Even given sufficient awareness and strategic emphasis on transitioning to systemic innovations for sustainability, uncertainty avoidance may lead organisations to falter in building such innovation capabilities and acting on sustainable innovation strategies. Difficulties in valuation of systemic innovations for sustainability, uncertainty of financial returns and technologies create outcome uncertainties that increase decision-making inconvenience. High investment costs manifest also as opportunity costs. Furthermore, institutional misalignment together with social and commercial uncertainty hamper the adoption and implementation of systemic innovations. 
Challenges of Structural impediments:

focus in incremental innovations

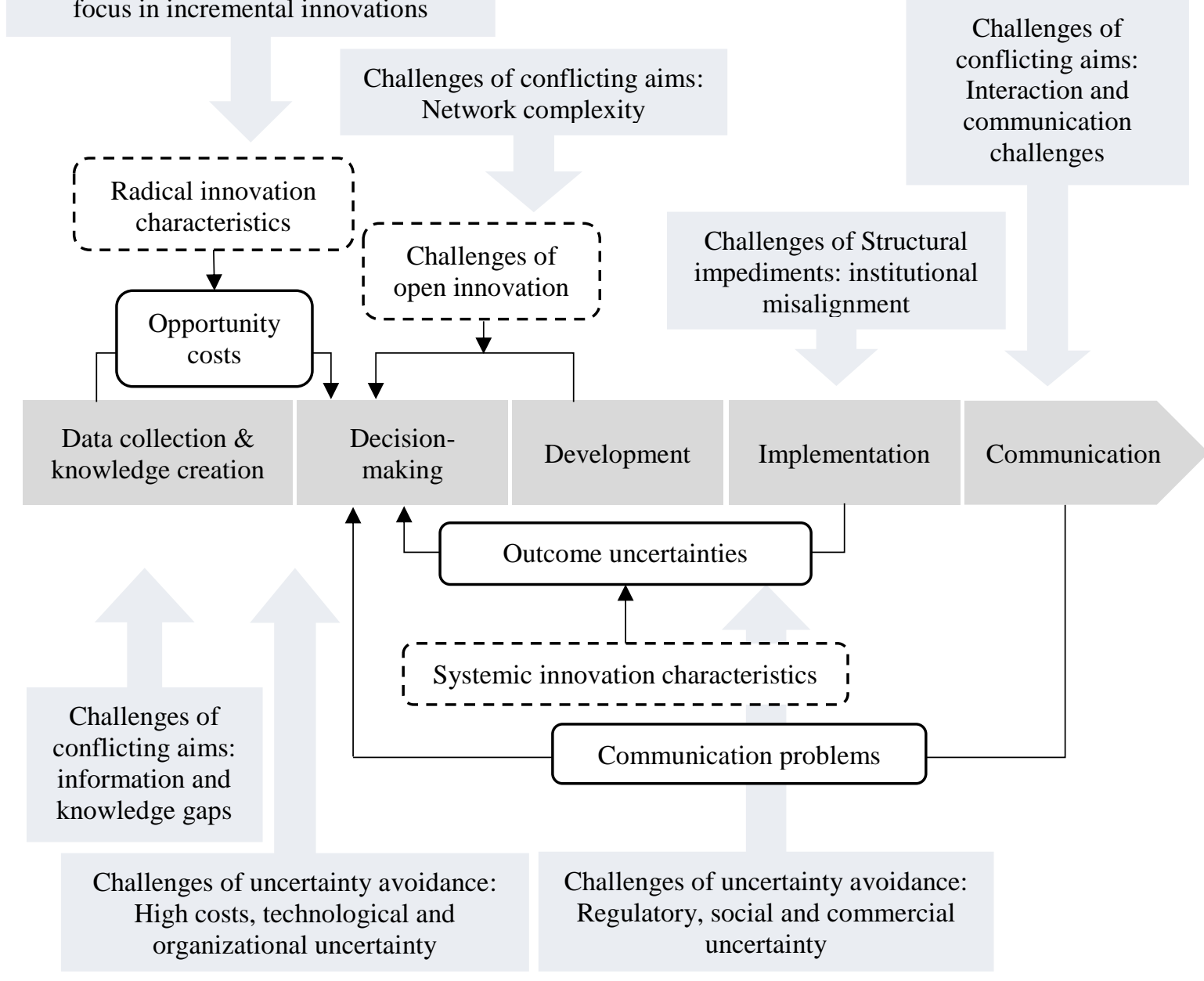

Figure 1. Decision-making challenges in innovation for sustainability

Decisions regarding systemic innovations for sustainability encounter cumulative issues across the innovation process. Companies are facing situations where they are required to invest without sufficient information and means to evaluate these projects versus other investments, i.e. not being able to evaluate the opportunity costs. The more radical the nature of the innovation is, the more it encounters inertia in the business environment, and displaces existing lines of business and business models, which are all difficult to account for. Systemic innovations also depend on the actions of the stakeholders, the management of which requires specific open innovation capabilities, such as networking, competence mapping, and relational and desorptive capabilities (Behnam et al., 2018). Finally, the captured value of the innovation is tied to communication capabilities as well, adding to the uncertainty about the outcome.

The cumulative nature of the challenges involved in delivering systemic innovations for sustainability may lead companies to focus on improving the wrong areas. Instead of building capabilities that would 
address the root issues - improving the innovation decision-making capacity to cope with uncertainty, stakeholder management and complexity - they may end up focusing on patching the symptomatic results of these by addressing individual phases or activities of the innovation process.

\section{Conclusion}

Our study of 13 companies from seven industries showed that firms' capabilities are yet to catch up with the unique demands set by systemic innovations for sustainability. To acquire the appropriate capabilities, firms should focus on building adaptive learning capacities and redesign processes to accommodate extensive uncertainty and collaboration, e.g. by integrating end-users into innovation processes (Zimmerling et al., 2017). This builds organisational resilience and positions firms as complex adaptive organisms (Inigo and Albareda, 2016). Such a mind-set will accelerate systemic innovations - not only by gaining confidence to act in uncertainty, but also by increasing the potential for radical and business model innovations through focus on the unexpected. Building capabilities for systemic innovation for sustainability is challenging, as best practice examples are not readily available. However, developing capabilities for open and radical innovation could help to address the challenges.

The literature and empirical findings show how issues of structural impediments, uncertainty avoidance and conflicting aims within and between the firms all contribute to the inaction and indecision witnessed in pursuing systemic innovations for sustainability. Even in firms with a strategic commitment to sustainability, innovation processes and capabilities are not yet developed to support the kinds of radical, systemic and collaborative actions required to make the transition. Organisations find themselves facing conditions that incentivize inertia in the transformation and succumb to uncertainty avoidance behaviors that can only be overcome by decisive management action.

This study encourages company and governmental decision-makers to invest in innovation- and sustainability -related education. Increasing the knowledge, understanding of the requirements and the development of skills (e.g. to evaluate and communicate sustainability value) in companies and among political decision-makers is a key in increasing the collaboration required for systemic innovations for sustainability. This helps in defining congruent goals between the actors and encouraging collaboration and open innovation, through which the risks of radical innovations may be lowered.

While we focused on the perceptions of leaders in large multinational companies, studying SMEs could yield complementary insights. Smaller firms have different innovation capabilities and have fewer complementary assets to support large-scale innovation projects. On the other hand, SMEs, in competition with incumbents, are more agile and (by necessity) willing to risk more with exploratory and innovative approaches. The needs for capability development could also be different for SMEs. This provides an interesting avenue for future research. 
Also, given that systemic innovation, by definition, involves multiple actors, further research following the Triple Helix concept (Etzkowitz and Leydesdorff, 2000) could discover effective policy options by explaining the systemic reactions that currently lead to unfavorable lock-in situations (Wesseling and Van der Vooren, 2017).

\section{References}

Accenture. "Special Edition: A Call to Climate Action" The UN Global Compact-Accenture CEO Study. (2015). https://www.unglobalcompact.org/library/3551 [Accessed 25 May 2018].

Adams, Richard, Jeanrenaud, S., Bessant, J., Denyer, D. and Overy, P. "Sustainability- oriented innovation: a systematic review." International journal of Management Reviews 18 no. 2 (2016): 180205.

Ambec, Stefan, and Lanoie, P. "Does it pay to be green? A systematic overview." Academy of Management Perspectives 22 (2008): 45-62.

Anttonen, Markku, Halme, M., Houtbeckers, E., and Nurkka, J. 'The other side of sustainable innovation: is there a demand for innovative services?" Journal of Cleaner Production 45 (2013): 89103.

Behnam, Sarah, Cagliano, R. and Grivaljo, M. "How should firms reconcile their open innovation capabilities for incorporating external actors in innovations aimed at sustainable development?" Journal of Cleaner Production 170 (2018): 950-965.

Bocken, Nancy, Short, S., Rana, P., and Evans S.“A literature and practice review to develop sustainable business model archetypes." Journal of cleaner production 65 (2014): 42-56.

Boons, Frank, Montalvo, C., Quist, J., and Wagner, M. "Sustainable innovation, business models and economic performance: an overview." Journal of Cleaner Production, 45 (2013): 1-8.

Boström, Magnus, Jönsson, A., Lockie, S., and Mol, A. "Sustainable and responsible supply chain governance: challenges and opportunities.” Journal of Cleaner Production 107 (2015): 1-7.

Corbin, Juliet, and Strauss, A. Basics of qualitative research: Techniques and procedures for developing grounded theory. 4rd ed. Newbury Park, CA: Sage (2015).

Eccles, Robert, Ioannou, I., and Serafeim, G. "The Impact of Corporate Sustainability on Organizational Processes and Performance.” Management Science 60, no. 11 (2014): 2835-2857.

Eisenhardt, Kathleen, and Graebner, M. "Theory building from cases: Opportunities and challenges." Academy of Management Journal 50, no. 1, (2007): 25-32. 
Eisenhardt, Kathleen, and Martin, J. "Dynamic capabilities: what are they?" Strategic Management Journal 21 (2000): 1105-1121.

Elkington, John. Cannibals with forks: the triple bottom line of sustainability. Gabriola Island: New Society Publishers (1997).

Etzkowitz, Henry, and Leydesdorff, L. "The dynamics of innovation: from National Systems and "Mode 2" to a Triple Helix of university-industry-government relations." Research policy 29 no. 2 (2000): 109-123.

Gaziulusoy, A. Idil, and Brezet, H. "Design for system innovations and transitions: a conceptual framework integrating insights from sustainability science and theories of system innovations and transitions." Journal of Cleaner Production 108 (2015): 558-568.

Hahn, Tobias, Figge, F., Pinkse, J., and Preuss, L. "Trade-offs in corporate sustainability: you can’t have your cake and eat it." Business Strategy and the Environment 19 (2010): 217-229.

Hall, Jeremy, Matos, S., Silvestre, B., and Martin, M. "Managing technological and social uncertainties of innovation: the evolution of Brazilian energy and agriculture." Technological Forecasting and Social Change, 78, no.7 (2011): 1147-1157.

Hansen, Erik G., Grosse-Dunker, F., and Reichwald, R. "Sustainability innovation cube - a framework to evaluate sustainability oriented innovations." International Journal of Innovation Management 13, no.4 (2009): 683-713.

Helfat, Constance, and Peteraf, M. "The dynamic resource-based view: capability lifecycles." Strategic Management Journal 24 (2003): 997-1010.

Inigo, Edurne, and Albareda, L. "Understanding sustainable innovation as complex adaptive system: a systemic approach to the firm." Journal of Cleaner Production 126 (2016): 1-20.

Lichtenthaler, Ulrich. "Open Innovation: Past Research, Current Debates, and Future Directions". Academy of Management Perspectives 25, no. 1 (2011): 75-93.

Lichtenthaler, Ulrich, and Lichtenthaler, E. “A Capability-Based Framework for Open Innovation: Complementing Absorptive Capacity.” Journal of Management Studies 46, no.8 (2009): 1315-1338.

Lin, Yuan-Hsu, and Tseng, M-L. "Assessing the competitive priorities within sustainable supply chain management under uncertainty." Journal of Cleaner Production 112 (2016): 2133-2144. 
Lockett, Helen, Johnson, M., Bastl, M., and Evans, S. "Product service systems and supply network relationships: an exploratory case study." Journal of Manufacturing Technology Management 22 (2011): 293-313.

Lopez, Rodriguez, Sakhel, A., and Busch, T. "Corporate investments and environmental regulation: The role of regulatory uncertainty, regulation-induced uncertainty, and investment history." European Management Journal 31, no.1 (2017): 91-101

Lozano, Rodriguez. "A holistic perspective on corporate sustainability drivers." Corporate Social Responsibility and Environmental Management 22, no.1 (2015): 32-44.

Markad, Jochen, Raven, R., and Truffer, B. "Sustainability transitions: An emerging field of research and its prospects." Research Policy 41 (2012): 955-967.

Medeiros, Janine, Ribeiro, J., and Cortimiglia, M. "Success factors for environmentally sustainable product innovation: a systematic literature review." Journal of Cleaner production 65 (2014): 76-86.

Mignon, Ingrid, and Bergek, A. "System- and actor-level challenges for diffusion of renewable electricity technologies: an international comparison." Journal of Cleaner Production 128 (2016): $105-115$.

Mylan, Josephine, Geels, F., Gee, S., McMeekin, A., and Foster, C. "Eco-innovation and retailers in milk, beef and bread chains: enriching environmental supply chain management with insights from innovation studies." Journal of Cleaner Production 107 (2014): 20-30.

Nidumolu, Ram, Prahalad, C., and Rangaswami, M. "Why Sustainability Is Now the Key Driver of Innovation." Harvard Business Review 8, no.9 (2009): 56-64.

Noppers, Ernst, Keizer, K., Bockarjova, M., and Steg, L. "The adoption of sustainable innovations: The role of Instrumental, environmental, and symbolic attributes for earlier and later adopters." Journal of Environmental Psychology 44 (2015): 74-84.

Roscoe, Samuel, Cousins, P., and Lamming, R. "Developing eco-innovations: a three stage typology for supply networks.” Journal of Cleaner Production 112 (2016): 1984-1959.

Schaltegger, Stefan, and Wagner, M. "Sustainable entrepreneurship and sustainability innovation: categories and interactions." Business strategy and the environment 20, no. 4 (2011): 222-237.

Seebode, Dorothea, Jeanrenaud, S., and Bessant, J. "Managing innovation for sustainability." $R \& D$ Management 42, no. 3 (2012): 195- 206. 
Schiederig, Tim, Tietze, F., and Herstatt, C. "Green innovation in technology and innovation management - an exploratory literature review." R\&D Management 42, no. 2 (2012): 180-192.

Silvestre, Bruno. "A hard nut to crack! Implementing supply chain sustainability in an emerging economy." Journal of cleaner production 96 (2015): 171-181.

Slater, Stanley, Mohr, J., and Sengupta, S. "Radical Product Innovation Capability: Literature Review, Synthesis, and Illustrative Research Propositions." The Journal of Product Innovation Management 31, no. 3 (2013): 552-566.

Teece, David. "Explicating dynamic capabilities: the nature and microfoundations of (sustainable) enterprise performance.” Strategic Management Journal 28 (2007): 1319-1350.

Teece, David. "Business models and dynamic capabilities." Long Range Planning 51, no. 1 (2017):40-49.

Teece, David, Pisano, G., and Shuen, A. "Dynamic capabilities and strategic management." Strategic Management Journal 18 (1997): 509-533.

Quist, Jaco, and Tukker, A. "Knowledge collaboration and learning for sustainable innovation and consumption: introduction to the ERSCP portion of this special volume." Journal of Cleaner Production 48 (2013): 167-175.

Van den Bosch, S.J.M., Brezet, J., and Vergragt, P. "How to kick off system innovation: a Rotterdam case study of the transition to a fuel cell transport system." Journal of Cleaner Production 13 (2015): 1027-1035.

Vezzoli, Carlo, Ceschin, F., Diehl, J., and Kohtala, C. "New design challenges to widely implement 'Sustainable Product-Service Systems'.” Journal of Cleaner production 97 (2015): 1-12.

Wesseling, Joeri H., and Van der Vooren, A. "Lock-in of mature innovation systems: the transformation toward clean concrete in the Netherlands." Journal of cleaner production 155 (2017): 114-124.

Winter, Sidney. “Understanding dynamic capabilities.” Strategic Management Journal 24 (2003): 991-995.

Xavier, Amanda, Naveiro, R., Aoussat, A., and Reyes, T. "Systematic literature review of ecoinnovation models: Opportunities and recommendations for future research." Journal of Cleaner Production 149 (2017): 1278-1302 
Yin, Robert. Case Study Research: Design and Methods. $5^{\text {th }}$ edition. Thousand Oaks, California: Sage Publications (2014).

Zimmerling, Eric, Purtik, H., and Welpe, I. "End-users as co-developers for novel green products and services e an exploratory case study analysis of the innovation process in incumbent firms." Journal of cleaner production 162 (2017): S51-S58. 